\title{
The prognostic value of pain
}

\section{catastrophizing in health-related quality of life judgments after Total knee arthroplasty}

\author{
Esther Yakobov ${ }^{1}$, William Stanish², Michael Tanzer ${ }^{3}$, Michael Dunbar $^{2}$, Glen Richardson ${ }^{2}$ and Michael J. L. Sullivan ${ }^{1 *}$
}

\begin{abstract}
Background: Total knee arthroplasty (TKA) is a highly effective procedure that yields reductions in pain and disability associated with end stage osteoarthritis (OA) of the knee. Quality of life instruments are frequently used to gauge the outcomes of total knee arthroplasty (TKA). However, research suggests that post-TKA reductions in symptom severity may not be the sole predictors of quality of life post-TKA. The primary objective of the present study was to examine the prognostic value of catastrophic thinking in health-related quality of life (HRQOL) judgments in patients with severe OA after TKA.
\end{abstract}

Methods: In this study we used a prospective cohort design to examine the value of pain catastrophizing in predicting HRQoL 1 year after TKA. Participants with advanced OA of the knee who were scheduled for TKA were recruited at one of three hospitals in Canada. The study sample consisted of 116 individuals (71 women, 45 men) who completed study questionnaires at their pre-surgical evaluation and 1 year after surgery. Hierarchical regression analysis was used to assess the unique contribution of pre-surgical pain catastrophizing to the prediction of post-surgical HRQoL judgments.

Results: The results of the hierarchical regression equation revealed that the overall model was significant, $F$ $(9,106)=8.3, p<001$, and accounted for $36.4 \%$ of the variance in the prediction of post-surgical physical component score of HRQoL. Pain catastrophizing was entered in the last step of the equation and contributed significant unique variance $(\beta=-.35, p<.001)$ to the prediction of post-surgical physical component score of HRQoL above and beyond the variance accounted for by demographic variables, co-morbid health conditions, baseline HRQOL, and post-surgical reductions in pain, joint stiffness and physical disability.

Conclusions: The current findings highlight the importance of pre-surgical catastrophic cognitions in influencing HRQoL judgments after TKA. The findings suggest that psychosocial interventions designed to reduce pain catastrophizing before TKA might contribute to better quality of life outcomes following surgery.

Keywords: Osteoarthritis, Pain catastrophizing, Health-related quality of life

\section{Background}

Total knee arthroplasty (TKA) has been shown to be effective for relieving pain, stiffness, mobility restrictions, and improving quality of life in patients with end-stage osteoarthritis $(\mathrm{OA})$ of the knee [1-3]. Health-related quality of life (HRQoL) instruments are often used to gauge the success of TKA [4]. Research suggests that individuals'

\footnotetext{
* Correspondence: michael.sullivan@mcgill.ca

'Department of Psychology, McGill University, 2001 McGill College, Room

1406, Montreal, Quebec H3A 1G1, Canada

Full list of author information is available at the end of the article
}

perceptions of their quality of life might provide more meaningful information about their physical, social, and emotional well-being than medical status variables and other objective measures of symptomatology [5-9]. HRQoL instruments are particularly useful as markers of treatment effectiveness for conditions where complete eradication of symptoms is not considered to be a feasible treatment objective [4].

Review of the literature suggests that reduction in pain and improvement in function are strong predictors of patients' reported improvement in HRQoL following TKA [10]. However, research also exists to indicate that

(c) The Author(s). 2018 Open Access This article is distributed under the terms of the Creative Commons Attribution 4.0 International License (http://creativecommons.org/licenses/by/4.0/) which permits unrestricted use, distribution, and reproduction in any medium, provided you give appropriate credit to the original author(s) and the source, provide a link to the Creative Commons license, and indicate if changes were made. The Creative Commons Public Domain Dedication waiver (http://creativecommons.org/publicdomain/zero/1.0/) applies to the data made available in this article, unless otherwise stated. 
improvement in condition specific symptoms such as knee pain and joint stiffness, does not always map directly onto patients' ratings of improvement on indices of quality of life. For example, results of a large investigation indicated that while pain relief after TKA was reported by $98 \%$ of patients, only approximately $60 \%$ of patients reported significant improvement in HRQoL [11]. Moreover, research indicates that despite objective markers of surgical success, up to $30 \%$ of patients remain dissatisfied with improvement in quality of life outcomes after TKA $[12,13]$. It has been proposed that in addition to disease-related variables, psychological variables might also play an important role in predicting HRQoL outcomes after TKA [11, 13]. To date systematic research examining psychological variables that can influence post-TKA HRQoL is lacking.

Catastrophic cognitions about pain have been shown to be associated with lower ratings of HRQoL in patients with various chronic pain conditions [14-17]. Pain catastrophizing has been broadly defined as a negative orientation towards actual or anticipated painful experiences [18]. Little research has been conducted to examine the association between pain catastrophizing and HRQoL in patients with severe $\mathrm{OA}$ of the knee. In one cross-sectional study, Somers and colleagues [19] reported a significant correlation between pain catastrophizing and a measure of HRQoL in patients with OA of the knee even after controlling for pain intensity. However, given the cross-sectional nature of the study, the direction of influence between pain catastrophizing and HRQoL remains uncertain. While it is possible that pain catastrophizing is contributing to negative HRQoL judgments, this relation may also simply reflect the psychological consequences of low HRQoL. In other words, low HRQoL may contribute to distress and exacerbate catastrophic cognitions. To date, the prospective relation between pre-surgical pain catastrophizing and post-surgical HRQoL judgments has yet to be systematically examined.

There are different pathways by which pain catastrophizing might impact on post-surgical HRQoL judgments. One possibility is that catastrophizing might compromise post-surgical recovery. Previous research has shown that high scores on pre-surgical catastrophizing are associated with persistent OA-specific pain severity and disability after TKA [20-22]. From this perspective, the negative impact of pain catastrophizing on post-surgical HRQoL would be entirely accounted for by problematic post-surgical outcomes. Another possibility is that pain catastrophizing might contribute to post-surgical HRQoL independent of its influence on surgical outcomes. The negative perceptual orientation of individuals high on pain catastrophizing might compromise coping strategies or lead them to focus excessively on their pain and avoid important life activities which, in turn, might have a negative impact on numerous domains of quality of life.

Demonstrating prospective relation between pain catastrophizing and post-surgical HRQoL judgments has important clinical implications. At present, efforts to maximize post-surgical HRQoL have primarily taken the form of improving medical or surgical management. Research showing independent contributions of psychological variables to post-surgical HRQoL would argue for the inclusion of psychological interventions to augment the impact of surgical procedures on post-surgical HRQoL. If HRQoL judgments are to be used as metrics to gauge the success and cost-effectiveness of surgical interventions for OA, there will be advantages to intervention approaches that target all possible variables that might influence post-surgical HRQoL.

Examining the contributions of pain catastrophizing to post-surgical HRQoL might also have important theoretical implications. Biopsychosocial models of surgical recovery are currently the dominant conceptual frameworks invoked to explain different recovery pathways. At present, however, these models have not been put forward with the degree of precision necessary to specify how different model components summate or interact to influence different recovery paths following surgery. Improving knowledge about the links between psychological and biological processes influencing post-surgical HRQoL might provide the conceptual foundation for the development of more effective interventions designed to maximize post-surgical HRQoL.

The purpose of the present study was to determine the value of pre-surgical pain catastrophizing in predicting HRQoL judgments after TKA. We tested the hypothesis that pre-surgical pain catastrophizing would be associated with lower post-surgical HRQoL independent of post-surgical reductions in pain, and physical disability and while controlling for demographic variables and co-morbid health conditions.

\section{Methods \\ Participants}

One hundred and sixteen individuals (71 women and 45 men) with severe OA of the knee who were scheduled for TKA at one of three hospitals in eastern Canada agreed to participate in this study. Participants ranged in age from 50 to 85 years. Fifty-two patients had TKA of the left knee, and 64 had TKA of the right knee. The majority of patients were married (85\%) and had completed at least 12 years of education (90\%).

\section{Measures}

Pain catastrophizing

The Pain Catastrophizing Scale (PCS) consists of 13 items that assess thoughts and feelings related to the 
experience of pain [18]. Participants respond to items using a 5-point Likert-type scale with responses ranging from $0=$ "not at all" to $4=$ "all the time". The scale has been shown to have high internal consistency (alpha $=0.87)$, good test-retest reliability $(r=0.7-0.8)$, and to be associated with heightened experience of pain in patients with a wide range of health conditions including osteoarthritis [18, 20, 22-25]. The PCS yields subscale scores of rumination, helplessness, and magnification. In the present study, only the total score was used. In the present study, the alpha coefficient was 0.94 .

\section{Co-morbidities}

Charlson Co-morbidity Index (CCI) [26] was used to assess the presence and severity of various co-morbid conditions that can affect TKA outcomes. The participants were asked to indicate the presence and severity of 13 different health conditions including hypertension, osteoarthritis of other joints, diabetes mellitus, and chronic obstructive pulmonary disease (COPD). The total score is calculated by summing the presence of different conditions indicated by the respondent [26].

\section{Pain, disability, and stiffness}

The Western Ontario and McMaster University Osteoarthritis Index (WOMAC) was used to evaluate disease specific outcomes; pain, joint stiffness and physical disability [27]. The WOMAC is a self-administered questionnaire that uses a 5-point Likert scale with responses ranging from $0=$ "none" to 4 = "extreme". Higher scores represent worse pain, stiffness, and disability. The WOMAC has been shown to be a valid and a reliable instrument for assessing disease specific outcomes in OA patients, and has been shown to be sensitive to changes in patients who underwent TKA [27-29].

\section{Health related quality of life}

Short-form health questionnaire (SF-12) was used to assess the physical and mental domains of quality of life. The SF-12 is a generic health status questionnaire that is derived from the SF-36, the original and longer version [30]. Scale scores range from 0 to 100 , with lower scores indicating worse symptoms. It is a reliable and a valid instrument that is composed of two component scores; physical component score (SF-12 PCS) and mental component score (SF-12 MCS), and is used to assess the overall health-related-quality of life in individuals with pain related conditions including OA [31].

\section{Procedure}

Patients in the current study were invited to participate at one of three hospitals where they were scheduled for TKA. They were informed that the research was concerned with the physical, psychological, and social determinants of recovery following surgery. To participate in the study, all patients provided written informed consent, and received $\$ 25$ as compensation for completing the questionnaires. This study was approved by the Research Ethics Boards of the McGill University Health Centre, the Hôpital Maisonneuve-Rosemont, and the Capital Health Authority of Nova Scotia. Participants were asked to complete the questionnaires at the time of their pre-surgical evaluation (within 4 weeks of surgery) and at their one-year post-surgical follow-up. Surgeries were performed by 11 surgeons from three different hospitals. By clinical standards, all patients in the study were considered surgical successes.

\section{Data analysis}

All measures (PCS, WOMAC, SF-12, Charlson Co-morbidity Index) showed a normal distribution with values of skewness below three and values of kurtosis below 10. Descriptive statistics were computed for sample characteristics on all pre- and post-surgical measures used in the study. To assess sex differences, independent sample t-tests were computed on all measures. Paired sample t-tests were computed to compare pre and post-surgical scores on the WOMAC and SF-12. Pearson correlations were used to examine the concurrent relations between pre-surgical measures of pain, disability, stiffness, mental and physical component scores of SF-12, and pain catastrophizing. A hierarchical regression was computed to assess the role of pre-surgical pain catastrophizing in the prediction of SF-12 PCS 1 year after surgery. Age, sex and BMI were entered in the first step. Co-morbid health conditions were entered in the second step. Baseline score of SF-12 PCS was entered in the third step. Change scores in disease specific variables (i.e., changes in raw scores from pre to post-WOMAC pain, disability, and stiffness) were entered in the fourth step. Pain catastrophizing was entered in the last step.

\section{Results \\ Sample characteristics}

Table 1 presents the means and standard deviations for all study variables. The mean age of the study sample was 67.1 years, with a range of 50 to 85 years. The mean BMI was 30.9, with a range of 20 to 45.2 . The distribution of age, BMI, and pre surgical scores on measures of pain, disability, stiffness, SF-12 PCS, SF-12 MCS and pain catastrophizing were comparable to (within one standard deviation from the mean) those reported in previous studies with TKA patients [8, 24, 32-34]. Men and women did not differ significantly on any demographic or study variable except for post-operative SF-12 PCS where men reported higher scores $(M=45.6$; SD $=9.7)$ than women $(\mathrm{M}=41.5 ; \mathrm{SD}=10.7) \mathrm{t}(114)=-2.1$, $p<.05$. As presented in Table 1 , pain catastrophizing 
Table 1 Zero-order correlations among study variables before surgery

\begin{tabular}{|c|c|c|c|c|c|c|c|c|c|c|c|c|}
\hline & M & SD & 1 & 2 & 3 & 4 & 5 & 6 & 7 & 8 & 9 & 10 \\
\hline \multicolumn{13}{|l|}{ 1. Sex } \\
\hline 2. Age & 67.1 & 8.2 & -.05 & & & & & & & & & \\
\hline 3. BMI & 30.9 & 5.2 & -.02 & $.36^{*}$ & & & & & & & & \\
\hline 4. Comorbid & 2.9 & 1.4 & -.08 & $.27^{*}$ & -.02 & & & & & & & \\
\hline 5. PCS & 12.6 & 11 & -.10 & -.10 & .08 & $.19^{*}$ & & & & & & \\
\hline 6. $\mathrm{PHQ}-9$ & 6.7 & 7.0 & -.02 & -.13 & .01 & .17 & $.51^{* *}$ & & & & & \\
\hline 7. Pain & 10.6 & 3.5 & -.07 & $-.28^{*}$ & $.21^{*}$ & .13 & $.36^{* *}$ & $.31^{*}$ & & & & \\
\hline 8. Function & 38.0 & 12.5 & .02 & $-.20^{*}$ & .17 & .20 & $.38^{* *}$ & $.39 * *$ & $.74^{* *}$ & & & \\
\hline 9. Stiffness & 4.7 & 1.5 & -.17 & $-.38^{* *}$ & $.20^{*}$ & .01 & $.30^{*}$ & $.31^{*}$ & $.68^{* *}$ & $-.67^{* *}$ & & \\
\hline 10. SF-12 PCS & 30.5 & 8.1 & .18 & .01 & -.12 & $-.24^{*}$ & $-.19^{*}$ & $-.25^{*}$ & $-.32^{* *}$ & $-.42^{* *}$ & $-.30^{*}$ & \\
\hline 11. SF-12 MCS & 43.1 & 10.5 & .03 & .06 & -.06 & $-.27^{*}$ & $-.48^{* *}$ & $-.57^{* *}$ & $-.27^{*}$ & $-.27^{* *}$ & $-.21^{*}$ & .06 \\
\hline
\end{tabular}

Note: $N=116$. PCS = Pain Catastrophizing Scale; PHQ-9 = Patient Health Questionnaire; BMI = Pre-surgical Body Mass Index; Comorbid = comorbid health conditions; Pain = WOMAC Pain Score; Function = WOMAC Physical Function Score; Stiffness = WOMAC Stiffness Score; SF-12 PCS = SF-12 Physical component score of Quality of Life; SF-12 MCS = SF-12 Mental component score of Quality of Life ${ }^{*} p<.05,{ }^{* *} p<.001$

was significantly correlated with pain severity, physical disability, SF-12 PCS and SF-12 MCS before surgery.

We also conducted zero order correlation analyses to examine the associations between age, BMI, and co-morbid health conditions with post-surgical component scores of SF-12. It was found that age, and BMI did not correlate with post-surgical component scores of SF-12. The number of co-morbid health conditions was associated with lower post-surgical SF-12 PCS $(r=-.28$, $p<.05)$ and SF-12 MCS $(r=-.20, \mathrm{p}<.05)$.

\section{Changes between pre and post- surgical outcomes variables}

Changes in pain, disability, stiffness, and HRQoL variables are presented in Table 2. As expected, there was a significant decrease in pain $(-7.2), t(115)=18.9, p$ $<.001, \mathrm{~d}=1.8$; stiffness $(-2.5) t(115)=15.1, p<.001, \mathrm{~d}$ $=1.4$; and disability $(-23.9), t(115)=18.8, p<.001 \mathrm{~d}=$ 1.7 from the pre-surgical to post-surgical evaluation. Consistent with previous findings [33], significant post-surgical improvements were reported for physical

Table 2 Difference between pre- and post- surgical symptom severity and quality of life variables

\begin{tabular}{lllll}
\hline Mean (SD) & Pre & Post & $P$ & Cohen's D \\
\hline Pain & $10.6(3.5)$ & $3.4(3.4)$ & $<.001$ & 1.8 \\
Disability & $38.0(12.5)$ & $14.1(11.4)$ & $<.001$ & 1.7 \\
Stiffness & $4.7(1.5)$ & $2.2(1.5)$ & $<.001$ & 1.4 \\
SF-12 PCS & $30.5(8.1)$ & $43.1(10.5)$ & $<.001$ & 1.2 \\
SF-12 MCS & $55.3(10.4)$ & $55.9(7.9)$ & ns & .05
\end{tabular}

Note: $N=116$. Pain = WOMAC Pain Score; Function = WOMAC Physical Function Score; Stiffness = WOMAC Stiffness Score; SF-12 PCS = SF-12 Physical component score of health-related quality of life; SF-12 MCS = SF-12 Mental component score of health-related quality of life
(12.6) $t(115)=-13.3, p<.001, \mathrm{~d}=1.2$ but not mental component score of SF-12.

\section{Predicting HRQoL}

Since the SF-12 MCS did not change as a result of surgery, the prospective relation between catastrophizing and HRQoL was tested only for the SF-12 PCS. The overall model was significant, $F(9,106)=8.30, p<.001$ and accounted for $41.3 \%$ of the variance $(36.4 \%$ adjusted). As shown in Table 3 , in the prediction of post-surgery SF-12 PCS, demographic variables entered in the first step failed to reach statistical significance. Co-morbid health conditions entered in the second step contributed $7 \%$ of variance in the prediction of post-surgery SF-12 PCS. Baseline SF-12 PCS entered in the third step contributed an additional $11.8 \%$ of variance to the regression equation. Changes in disease specific variables from pre- to post- surgery entered in the fourth step contributed $7.8 \%$ of the variance in the prediction of post-surgical SF-12 PCS. Pain catastrophizing entered in the last step accounted for additional 10.8\% of the variance in the prediction of post-surgical SF-12 PCS. Examination of the standardized beta weights from the final regression equation indicated that only baseline SF-12 PCS $(\beta=.37, p<.001)$ and pain catastrophizing $(\beta$ $=-.35, p<.001)$ contributed significant unique variance to the prediction of post-surgical SF-12 PCS.

\section{Discussion}

The aim of the current study was to examine the prognostic value of pain catastrophizing in HRQoL judgments following TKA. Replicating the results of previous research with individuals with $\mathrm{OA}$, pain severity and physical disability were associated with lower scores on a measure of HRQoL before surgery [35]. The results of 
Table 3 Regression analyses predicting post-surgical physical component of quality of life

\begin{tabular}{|c|c|c|c|}
\hline & $\beta$ & $p$ & $R^{2}$ change \\
\hline \multicolumn{4}{|c|}{$\begin{array}{l}\text { Dependent }=\text { Physical component score of health-related quality of life } \\
1 \text { year follow-up }\end{array}$} \\
\hline \multicolumn{4}{|l|}{ Step 1} \\
\hline Age & .00 & .98 & \\
\hline Sex & .07 & .35 & \\
\hline BMI & -.05 & .56 & .04 \\
\hline \multicolumn{4}{|l|}{ Step 2} \\
\hline Comorbid & -.13 & .12 & .07 \\
\hline \multicolumn{4}{|l|}{ Step 3} \\
\hline SF-12 PCS T1 & .37 & .00 & .12 \\
\hline \multicolumn{4}{|l|}{ Step 4} \\
\hline$\Delta$ Function & .08 & .48 & \\
\hline$\Delta$ Pain & .16 & .17 & \\
\hline$\Delta$ Stiffness & .06 & .54 & .08 \\
\hline \multicolumn{4}{|l|}{ Step 5} \\
\hline PCS & -.35 & .00 & .11 \\
\hline
\end{tabular}

Note: $N=116$. BMI = Body Mass Index; Comorbid = comorbid health conditions; $\Delta$ Pain $=$ difference between pre and post-surgical WOMAC Pain Score; $\Delta$ Function = difference between pre and post-surgical WOMAC Physical Function Score; $\triangle$ Stiffness = difference between pre and post-surgical WOMAC Stiffness Score; SF-12 PCS T1 = SF-12 Physical component score of health-related quality of life at baseline; PCS = Pain Catastrophizing Scale

Standardized beta $(\beta)$ is reported for the final step

the present study extend previous research by showing that high scores on pre-surgical pain catastrophizing predict lower scores on the physical component of HRQoL following TKA, independent of demographic variables, baseline SF-12 PCS, co-morbid health conditions, and reductions in pain severity, disability, and stiffness.

Gender, co-morbid health conditions, and obesity have been discussed as potential factors that can influence quality of life post-TKA [12]. In agreement with previous research, the results of the present study revealed that the number of co-morbid health conditions was significantly associated with lower post-surgical HRQoL [36]. Also consistent with previous research, the present study evidenced higher SF-12 PCS in men than in women after TKA [37]. Contrary to previous research findings, we did not find associations between BMI and post-TKA outcomes. This finding might be explained by a low variability in BMI in the present sample, with most scores (90.5\%) falling in the overweight range. In agreement with previous research, the present study revealed that age was not associated with post-surgical HRQoL [38].

In recent years, there has been a growing interest in examining psychological contributions to health-related variables and recovery trajectories following TKA [39]. The finding that reduction in pain is not always directly proportional to patients' reports of improved well-being has led researchers to search for other possible predictors of post-surgical HRQoL. Of interest in the present study was whether pain catastrophizing, measured before surgery, contributed to the prediction of post-surgical HRQoL. The pattern of findings suggests that pre-surgical pain catastrophizing is prospectively associated with lower post-surgical SF-12 PCS, above and beyond demographic variables, co-morbid health conditions and reductions in pain, and physical disability.

There could be several explanations for the present findings. Catastrophic cognitions about pain have been shown to interfere with fundamental neural processes related to pain perception through excessive attention to, anticipation of, and heighted emotional responses to pain $[40,41]$. This hypervigilance to the threat value of pain might predispose high catastrophizers to avoidance of life activities perceived as potentially pain inducing [42]. Indeed, it has been shown that high catastrophizing in patients with $\mathrm{OA}$ undermined the willingness to engage in demanding physical activities, even though such activities are important for managing pain and disability [23]. Activity avoidance might also have a negative influence on HRQoL by depriving the individual from participating in important life activities, and from experiencing positive social interactions, potentially leading to physical deconditioning and social isolation. Additionally, pain catastrophizers are thought to possess 1 "pain schema" comprised of negative information about pain. Pain-related cognitive distortions might lead the individual to magnify the experience of pain, and adopt pessimistic beliefs about their ability to cope with pain [18]. It is also possible that a cognitive bias towards excessively negative information about pain may lead the individual to discount positive surgery outcomes (i.e., significant reduction in pain and disability) and report lower improvement in $\mathrm{HRQoL}$ despite significant reduction in symptom severity.

The results of hierarchical regression analysis revealed that demographic variables, pre-surgical HRQoL, co-morbid health conditions, reductions in symptom severity and physical disability, and pre-surgical pain catastrophizing accounted for approximately $36 \%$ of the variance in the prediction of post-surgical HRQoL, leaving $64 \%$ of the variance not accounted for by these variables. Other factors that have been associated with lower HRQoL include fatigue, mental health conditions, poor quality of sleep, lower socioeconomic status, and reduced social network [43-46]. It is possible that these variables might also contribute to lower $\mathrm{HRQ}$ oL after TKA despite significant improvement in symptom severity, and independently from co-morbid health conditions and pain catastrophizing. 
Osteoarthritis is the most common form of arthritis, and is the leading cause of disability in North America $[47,48]$. With changing demographics, these figures are expected to increase substantially over the next decade. These figures are alarming, and signal that interventions designed to reduce the burden of OA are of increasing priority. At present, interventions designed to improve HRQoL in individuals with severe OA of the knee are primarily geared towards symptom reduction. Consistent with the results of previous investigations, the results of the present study suggest that a measure of pain catastrophizing should be considered as part of standard screening of individuals being considered for TKA. Targeting catastrophic thinking in patients at risk before surgery might be beneficial for improving post-surgical quality of life.

Psychosocial interventions combining cognitive-behavioural approaches to target catastrophic cognitions have been shown to be effective in promoting faster resumption of occupational activities and improved well-being in individuals with musculoskeletal injuries, low back pain, and fibromyalgia [49-52]. In vivo exposure techniques that enable patients to successfully experience and habituate to movements or activities that they have been avoiding have also been shown to decrease pain, and disability in patients with low back pain $[53,54]$. It is possible that exposure techniques challenge and subsequently reduce catastrophic cognitions. Given a degree of success of these interventions in the context of persistent pain, adapting these interventions for individuals with OA holds promise.

The findings of the present study must be interpreted with caution. The study sample size was modest and replication with larger data sets is needed to bolster confidence in the validity and reliability of the present findings. The absence of process measures compromises the ability to make confident statements about the specific pathways by which pain catastrophizing influences HRQoL after TKA. Finally, although the discussion proceeded from the perspective that pre-surgical pain catastrophizing contributes to lower HRQoL after surgery, it is very likely that this association is bi-directional. In other words, while it is possible that pain catastrophizing contributed to lower HRQoL, it might also be possible that low HRQoL led to increased catastrophizing. For example, HRQoL might have been influenced by other factors not measured in the present study (i.e., co-morbid mental health conditions) that in turn might augment catastrophic cognitions. Despite these limitations, this was the first study to show that pre-surgical pain catastrophizing plays an important role in determining perceived HRQoL following TKA, above and beyond improvement in symptom severity, and independently from comorbid health conditions.

\section{Conclusion}

The findings of the present study suggest that pain catastrophizing impacts on HRQoL despite significant reduction in pain, disability and stiffness after TKA, highlighting the importance for screening and targeting problematic cognitions before TKA. Future research is needed to determine whether screening and intervention for pain catastrophizing before surgery may improve HRQoL post-TKA.

\section{Abbreviations \\ BMI: Body mass index; CCl: Charlson Co-morbidity Index; HRQoL: Health- related quality of life; OA: Osteoarthritis; PCS : Pain Catastrophizing Scale; SF- 12 : Short-form health questionnaire; SF-12 MCS: Mental health component score of the short-form health questionnaire; SF-12 PCS: Physical health component score of the short-form health questionnaire; TKA: Total knee arthroplasty; WOMAC: Western Ontario and McMaster University Osteoarthritis Index}

\section{Acknowledgements}

The authors thank Karen Smith, Donalda Dickey, Allan Hennigar, Kory Arsenault and Anne-Marie Laliberté for their assistance in participant recruitment and data collection.

\section{Funding}

This research was supported by funds from the Canadian Institutes for Health Research (award number MOP-119542), and by funds from Canada Research Chairs, and by funds from Vanier Canada Graduate Scholarship.

Availability of data and materials

The datasets generated and/or analyzed during the present study are available from the corresponding author on reasonable request.

Authors' contributions

MJLS, WS, MT, MD, and GR designed the study. WS, MT, MD, GR were involved in data collection. EY was the involved in conceptualization of the study and analyzed the data, MJLS and EY wrote the manuscript. All authors have read and approved the final manuscript.

Ethics approval and consent to participate

All procedures performed in this study were in accordance with the ethical standards of the Research Ethics Boards of the McGill University Health Centre, the Hôpital Maisonneuve-Rosemont, the Capital Health Authority of Nova Scotia, and with the 1964 Helsinki declaration and its later amendments.

\section{Consent for publication}

Informed consent was obtained from all individual participants included in the study.

\section{Competing interests}

The authors declare that they have no competing interests.

\section{Publisher's Note}

Springer Nature remains neutral with regard to jurisdictional claims in published maps and institutional affiliations.

\section{Author details}

'Department of Psychology, McGill University, 2001 McGill College, Room 1406, Montreal, Quebec H3A 1G1, Canada. Department of Surgery, Dalhousie University, Halifax, Canada. ${ }^{3}$ Department of Surgery, McGill University, Montreal, Canada. 


\section{Received: 31 October 2017 Accepted: 11 June 2018}

Published online: 18 June 2018

\section{References}

1. Callahan CM, Drake BG, Heck DA, Dittus RS. Patient outcomes following tricompartmental total knee replacement. A meta-analysis. JAMA. 1994;271: 1349-57.

2. Cram P, Lu X, Kates SL, Singh JA, Li Y, Wolf BR. Total knee arthroplasty volume, utilization, and outcomes among Medicare beneficiaries, 1991-2010. JAMA. 2012;308:1227-36

3. Rasanen P, Paavolainen P, Sintonen H, Koivisto AM, Blom M, Ryynanen OP, Roine RP. Effectiveness of hip or knee replacement surgery in terms of quality-adjusted life years and costs. Acta Orthop. 2007;78:108-15.

4. Burckhardt C, Anderson K. The quality of life scale (QOLS): reliability, validity, and utilization. Health Qual of Life Outcomes. 2003:1:60.

5. Angst F, Stucki G, Aeschlimann A. Quality of life assessment in osteoarthritis. Expert Rev Pharmacoecon Outcomes Res. 2003;3:623-36.

6. Bruyere O, Honore A, Rovati LC, Giacovelli G, Henrotin YE, Seidel L, Reginster JY. Radiologic features poorly predict clinical outcomes in knee osteoarthritis. Scand J Rheumatol. 2002:31:13-6.

7. Dunbar MJ. Subjective outcomes after knee arthroplasty. Acta Orthop Scand Suppl. 2001;72:1-63.

8. Escobar A, Quintana JM, Bilbao A, Azkarate J, Guenaga JI, Arenaza JC, Gutierrez LF. Effect of patient characteristics on reported outcomes after total knee replacement. Rheumatol. 2007:46:112-9.

9. Farr li J, Miller LE, Block JE. Quality of life in patients with knee osteoarthritis: a commentary on nonsurgical and surgical treatments. Open Orthop J. 2013;7:619-23.

10. da Silva RR, Santos AAM, de Sampaio Carvalho Júnior J, Matos MA. Quality of life after total knee arthroplasty: systematic review. Rev Bras Ortop. 2014; 49.520-7.

11. Franklin PD, Li W, Ayers DC. The Chitranjan Ranawat award: functional outcome after total knee replacement varies with patient attributes. Clin Orthop Relat Res. 2008;466:2597-604.

12. Canovas F, Dagneaux L. Quality of life after total knee arthroplasty. Orthop Traumatol Surg Res. 2018;104:S41-6.

13. Wylde V, Dieppe P, Hewlett S, Learmonth ID. Total knee replacement: is it really an effective procedure for all? Knee. 2007;14:417-23.

14. Borsbo B, Peolsson M, Gerdle B. Catastrophizing, depression, and pain: correlation with and influence on quality of life and health - a study of chronic whiplash-associated disorders. J Rehabil Med. 2008;40:562-9.

15. Holroyd KA, Drew JB, Cottrell CK, Romanek KM, Heh V. Impaired functioning and quality of life in severe migraine: the role of catastrophizing and associated symptoms. Cephalalgia. 2007:27:1156-65.

16. Lame IE, Peters ML, Vlaeyen JW, Kleef M, Patijn J. Quality of life in chronic pain is more associated with beliefs about pain, than with pain intensity. Eur J Pain. 2005;9:15-24.

17. Severeijns $R$, van den Hout MA, Vlaeyen JW, Picavet HS. Pain catastrophizing and general health status in a large Dutch community sample. Pain. 2002; 99:367-76.

18. Sullivan MJL, Bishop S, Pivik J. The pain catastrophizing scale: development and validation. Psychol Assessment. 1995;7:524-32

19. Somers TJ, Keefe FJ, Carson JW, Pells JJ, Lacaille L. Pain catastrophizing in borderline morbidly obese and morbidly obese individuals with osteoarthritic knee pain. Pain Res Manag. 2008;13:401-6.

20. Edwards RR, Haythornthwaite JA, Smith MT, Klick B, Katz JN. Catastrophizing and depressive symptoms as prospective predictors of outcomes following total knee replacement. Pain Res Manag. 2009;14:307-11.

21. Forsythe ME, Dunbar MJ, Hennigar AW, Sullivan MJL, Gross M. Prospective relation between catastrophizing and residual pain following knee arthroplasty: two-year follow-up. Pain Res Manag. 2008;13:335-41.

22. Riddle DL, Wade JB, Jiranek WA, Kong X. Preoperative pain catastrophizing predicts pain outcome after knee arthroplasty. Clin Orthop Relat Res. 2010; 468:798-806.

23. Somers TJ, Keefe FJ, Pells JJ, Dixon KE, Waters SJ, Riordan PA, Blumenthal JA McKee DC, LaCaille L, Tucker JM, et al. Pain catastrophizing and pain-related fear in osteoarthritis patients: relationships to pain and disability. J Pain Symptom Manag. 2009:37:863-72

24. Sullivan MJL, Tanzer M, Stanish W, Fallaha M, Keefe FJ, Simmonds M, Dunbar M. Psychological determinants of problematic outcomes following Total knee arthroplasty. Pain. 2009;143:123-9.
25. Keefe FJ, Brown GK, Wallston KA, Caldwell DS. Coping with rheumatoid arthritis pain: catastrophizing as a maladaptive strategy. Pain. 1989:37:51-6.

26. Charlson ME, Pompei P, Ales KL, MacKenzie CR. A new method of classifying prognostic comorbidity in longitudinal studies: development and validation. J Chronic Dis. 1987;40:373-83.

27. Bellamy N, Buchanan W, Goldsmith G, Campbell J, Stitt L. Validation study of WOMAC: a health status instrument for measuring clinically important patient relevant outcomes to antirheumatic drug therapy in patients with osteoarthritis of hip or knee. J Rheumatol. 1988;15:1833-40.

28. Bellamy N. Pain assessment in osteoarthritis: experience with the WOMAC osteoarthritis index. Semin Arthritis Rheu. 1989:18:14-7.

29. Bellamy N, Kean WF, Buchanan WW, Gerecz-Simon E, Campbell J. Double blind randomized controlled trial of sodium meclofenamate (Meclomen) and diclofenac sodium (Voltaren): post validation reapplication of the WOMAC osteoarthritis index. J Rheumatol. 1992:19:153-9.

30. Stewart AL, Hays RD, Ware JE Jr. The MOS short-form general health survey. Reliability and validity in a patient population. Med Care. 1988;26:724-35.

31. Gandhi SK, Salmon JW, Zhao SZ, Lambert BL, Gore PR, Conrad K. Psychometric evaluation of the 12-item short-form health survey (SF-12) in osteoarthritis and rheumatoid arthritis clinical trials. Clin Ther. 2001;23:1080-98.

32. Clement ND, Burnett R. Patient satisfaction after total knee arthroplasty is affected by their general physical well-being. Knee Surg Sports Traumatol Arthrosc. 2013;21:2638-46.

33. Hartley RC, Barton-Hanson NG, Finley R, Parkinson RW. Early patient outcomes after primary and revision total knee arthroplasty. A prospective study. J Bone Joint Surg Br. 2002;84:994-9.

34. Nunez M, Nunez E, del Val Luis J, Ortega R, Segur J, Hernandez M, Lozano L, Sastre S, Macule F. Health-related quality of life in patients with osteoarthritis after total knee replacement: factors influencing outcomes at 36 months of follow-up. Osteoarthr Cartil. 2007:15:1001-7.

35. Jakobsson U, Hallberg IR. Pain and quality of life among older people with rheumatoid arthritis and/or osteoarthritis: a literature review. J Clin Nurs. 2002;11:430-43.

36. Singh JA, Lewallen DG. Are outcomes after total knee arthroplasty worsening over time? A time-trends study of activity limitation and pain outcomes. BMC Musculoskelet Disord. 2014;15:440.

37. Cherian JJ, O'Connor MI, Robinson K, Jauregui JJ, Adleberg J, Mont MA. A prospective, longitudinal study of outcomes following Total knee arthroplasty stratified by gender. J Arthroplast. 2015;30:1372-7.

38. Kuperman EF, Schweizer M, Joy P, Gu X, Fang MM. The effects of advanced age on primary total knee arthroplasty: a meta-analysis and systematic review. BMC Geriatr. 2016;16:41.

39. Vissers MM, Bussmann JB, Verhaar JA, Busschbach JJ, Bierma-Zeinstra SM Reijman M. Psychological factors affecting the outcome of total hip and knee arthroplasty: a systematic review. Semin Arthritis Rheum. 2012:41:576-88.

40. Gracely RH, Geisser ME, Giesecke T, Grant MA, Petzke F, Williams DA, Clauw DJ. Pain catastrophizing and neural responses to pain among persons with fibromyalgia. Brain. 2004;127:835-43.

41. Seminowicz DA, Davis KD. Cortical responses to pain in healthy individuals depends on pain catastrophizing. Pain. 2006;120:297-306

42. Vlaeyen JW, Kole-Snijders AM, Rotteveel AM, Ruesink R, Heuts PH. The role of fear of movement/(re)injury in pain disability. J Occup Rehabil. 1995;5: 235-52.

43. Baldwin CM, Griffith KA, Nieto FJ, O'Connor GT, Walsleben JA, Redline S. The Association of Sleep-Disordered Breathing and Sleep Symptoms with quality of life in the sleep heart health study. Sleep. 2001;24:96-105.

44. Kim SH, Son BH, Hwang SY, Han W, Yang J-H, Lee S, Yun YH. Fatigue and depression in disease-free breast Cancer survivors: prevalence, correlates, and association with quality of life. J Pain Symptom Manag. 2008:35:644-55.

45. Rapaport MH, Clary C, Fayyad R, Endicott J. Quality-of-life impairment in depressive and anxiety disorders. Am J Psychiatry. 2005;162:1171-8.

46. Pinquart M, Sörensen S. Influences of socioeconomic status, social network, and competence on subjective well-being in later life: a meta-analysis. Psychol Aging. 2000;15:187-224.

47. Arthritis Alliance of Canada. The impact of arthritis in Canada: today and over the next 30 years. 2011, 11-4, 28-32. Available at: http://www. arthritisalliance.ca/docs/. Accessed Aug 2017.

48. Centers for Disease Control and Prevention. National Public Health Agenda for Osteoarthritis 2010. Available at: http://www.cdc.gov/arthritis/docs/ oaagenda.pdf. Accessed July 2017. 
49. Sullivan AH. Psychosocial treatment techniques to augment the impact of physiotherapy interventions for low back pain. Physiother Can. 2010;62:180-9.

50. Sullivan AH, Ellis T. Targeting catastrophic thinking to promote return to work in individuals with fibromyalgia. J Cognit Psychother. 2012;26:130-42

51. Sullivan AH, Rhodenizer T, Stanish WD. A psychosocial risk factor-targeted intervention for the prevention of chronic pain and disability following whiplash injury. Physical Ther. 2006;86:8-18.

52. Sullivan MJ. What is the clinical value of assessing pain-related psychosocial risk factors? Pain Manag. 2013;3:413-6

53. Vlaeyen JW, de Jong J, Geilen M, Heuts PH, van Breukelen G. Graded exposure in vivo in the treatment of pain-related fear: a replicated singlecase experimental design in four patients with chronic low back pain. Behav Res Ther. 2001;39:151-66.

54. Vlaeyen JW, de Jong J, Geilen M, Heuts PH, van Breukelen G. The treatment of fear of movement/(re)injury in chronic low back pain: further evidence on the effectiveness of exposure in vivo. Clin J Pain. 2002;18:251-61.

Ready to submit your research? Choose BMC and benefit from:

- fast, convenient online submission

- thorough peer review by experienced researchers in your field

- rapid publication on acceptance

- support for research data, including large and complex data types

- gold Open Access which fosters wider collaboration and increased citations

- maximum visibility for your research: over $100 \mathrm{M}$ website views per year

At BMC, research is always in progress.

Learn more biomedcentral.com/submissions 